\title{
The role of ocean velocity in chlorophyll variability. A modelling study in the Alboran Sea
}

\author{
Jordi Solé $^{1}$, Joaquim Ballabrera-Poy ${ }^{1}$, Diego Macías ${ }^{2}$, Ignacio A. Catalán ${ }^{3}$ \\ ${ }^{1}$ Institut de Ciències del Mar, CSIC, 08003 Barcelona, Catalunya, Spain. E-mail: jsole@icm.cat \\ ${ }^{2}$ European Commission, Joint Research Centre, Via E. Fermi, 21027, Ispra, Italy. \\ ${ }^{3}$ IMEDEA (CSIC-UIB), Miquel Marquès 21, 07910 Esporles, Mallorca, Spain.
}

\begin{abstract}
Summary: In this work we focus on the Alboran Sea (western Mediterranean) to relate wind field and ocean velocity variability with chlorophyll $a$ (Chl $a$ ) behaviour, using a 2-km resolution, coupled 3D ocean circulation-NPZD model (ROMS). The analysis is done in three steps. First, we split the seasonal and residual contribution for the fields under study. Second, we calculate the corresponding empirical orthogonal functions (EOFs) for the seasonal and residual parts. Finally, we relate each pair of variables for both seasonal and residual contribution EOFs. The results reported here allow the links between wind and Chl $a$ to be quantified. We explain these links in terms of the ocean velocity field acting as a driver of Chl $a$ variability. The results show that, although the seasonal part of the Chl $a$ field is modulated by the vertical velocity, the residual component is modulated by the horizontal velocity components. Vertical velocities are responsible, through coastal upwelling, for Chl $a$ bloom enhancement, while horizontal velocities spread coastal Chl $a$ surface blooms off-shore.
\end{abstract}

Keywords: Alboran Sea; chlorophyll; wind forcing; primary production; ocean biogeochemical model; ROMS model; EOF analysis.

El papel de la velocidad oceánica en la variabilidad de la clorofila. Un estudio de modelado en el mar de Alborán

Resumen: En este trabajo nos centramos en el mar de Alborán (Mediterráneo Occidental) para relacionar los campos de velocidad del viento y del océano con la variabilidad de la clorofila $a(\mathrm{Chl} a)$, utilizando un modelo de circulación 3D-NPZD (ROMS-Fennel) con una resolución de $2 \mathrm{~km}$. El análisis se realiza en tres pasos. En primer lugar, separamos la contribución estacional y el residuo para todos los campos de estudio. En segundo lugar, calculamos las correspondientes funciones ortogonales empíricas (EOFs) para las components estacionales y residuales. Por último, relacionamos cada par de variables para ambos, EOFs estacionales y residuales. Los resultados permiten la cuantificación de las relaciones entre el viento y la clorofila. Explicamos estas relaciones en términos del campo de velocidades del océano que actúa como motor de la variabilidad de la Chl $a$. Los resultados muestran que, aunque la parte estacional de campo Chl $a$ es modulada por la velocidad vertical, la componente residual es modulada por las componentes de la velocidad horizontal. Las velocidades verticales son responsables, a través de la surgencia costera, de incrementar el valor de la proliferación de Chl $a$, mientras que las velocidades horizontales extienden estas proliferaciones costeras superficiales a mar abierto.

Palabras clave: mar de Alborán; clorofila; forzamiento del viento; producción primaria; modelo oceánico biogeoquímico; modelo ROMS; análisis EOF.

Citation/Como citar este artículo: Solé J., Ballabrera-Poy J., Macías D., Catalán I.A. 2016. The role of ocean velocity in chlorophyll variability. A modelling study in the Alboran Sea. Sci. Mar. 80S1: 249-256. doi: http://dx.doi.org/10.3989/ scimar.04290.04A

Editor: J.L. Pelegrí.

Received: June 15, 2015. Accepted: April 27, 2016. Published: September 30, 2016.

Copyright: @ 2016 CSIC. This is an open-access article distributed under the terms of the Creative Commons Attribution (CC-by) Spain 3.0 License.

\section{INTRODUCTION}

Ocean primary production is usually controlled by upwelling, entrainment and/or mixing of high nutrient subsurface water into the euphotic zone (Marra 1980). Knowledge of the causes and drivers of primary production is crucial to understand the whole ocean eco- system. Chlorophyll $a(\mathrm{Chl} a$ ) concentration deduced from satellite data (O'Reilly et al. 1998, Nieves et al. 2007) and from fluorometers (Coble et al. 2007) in oceanographic campaigns is normally used as a proxy for ocean primary production. Eddies, sub-mesoscale structures (McGillicuddy et al. 2007, Mahadevan et al. 2008, McGillicuddy et al. 2008) and vertical veloci- 
ties in upwelling areas (Estrada et al. 1985, GEOHAB 2005, Patti et al. 2008) can have a determinant role in Chl blooms. The role played by vertical velocities in modulating the biological activity through phytoplankton growth, mainly by bringing nutrients to the photic zone, has been long recognized (McGillicuddy et al. 2008). In some particular cases, vertical velocities can be driven by surface wind variability (Solé et al. 2012). However, the role played by ocean velocity components in the seasonal or residual parts of $\mathrm{Chl} a$ variability is currently an interesting subject, which has not been extensively explored. This study aims to give some insights into the role of ocean velocities on Chl $a$ variability in the Alboran Sea.

The dynamics of the Alboran Sea area (Fig. 1) is strongly controlled by zonal wind, as has been shown in previous works (Baldacci et al. 2001, Macías et al. 2008, 2011, Solé et al. 2012). It has been demonstrated that changes in the zonal wind have a strong effect on the ecosystem behaviour, through primary production influence (Sarhan et al. 2000, Macías et al. 2007, Macías et al. 2008, Oguz et al. 2015). The changes in zonal wind affect ocean surface structures and patterns such as gyres, the Almeria-Oran front (AOF) and the Algerian Current (see Fig. 1). Particularly important for $\mathrm{Chl} a$ blooms is the southern Iberian Peninsula coastal upwelling caused by the Atlantic Jet and the meridional displacement of the Western Alboran Gyre (WAG, see Macías et al. 2008). However, the extent to which the Chl $a$ inter-annual and intra-annual variability in the Alboran Sea is induced by such intrinsic internal atmospheric and ocean dynamics is a key question that remains to be fully understood. Particularly, how the ocean dynamics can affect the spatial and temporal distribution of the chlorophyll pattern and bloom occurrence in coastal and open sea areas is an interesting issue that requires further research. Numerical simulation data offer the opportunity to give some insights into these questions and, more generally, into how the atmosphere affects the marine ecosystem.

We use the ROMS model (www.myroms.org) to study how the previously reported atmospheric variability is propagated to the ecosystem and how ocean vertical velocities enhance the phytoplankton blooms in the area through nutrient enrichment of the photic zone. The main objective of our work is to provide additional insights into how the kinetic energy of wind affects ocean physical variables and to determine the ocean velocity components that may play an important role in the enhancement of ocean Chl $a$ in the area. To fulfil this aim, we analyse $\mathrm{Chl} a$ behaviour by splitting its variability into seasonal and residual. The residual part is caused by the amplification of small perturbations due to the presence of non-linearities in the model equations and differs from the typical seasonal system variability. When the initial residual, although fed by small perturbations in the model inputs, becomes a coherent pattern, it will interact with the physical dynamical structures of the system.

The paper is structured as follows. The next section introduces the methodological approach, specifically detailing the model implementation and the output model data analysis. We then show the results and discuss them in the context of previous studies.

\section{MATERIALS AND METHODS}

\section{Model}

A climatological simulation of the Alboran Sea area was run using the Regional Ocean Model System (ROMS: www.myroms.org), a free-surface, terrain-following, primitive equations ocean model. ROMS includes accurate and efficient physical and numerical algorithms (Shchepetkin and McWilliams 2003, 2005) and several coupled biogeochemical models (Powell et al. 2006, Fennel et al. 2006). A four-compartment (nitrogen, phytoplankton, zooplankton and detritus), N-based biogeochemical model (Fennel et al. 2006) was run coupled on-line with the hydrodynamics model. The Chl $a$ concentration is calculated from the nitrogen contained in the phytoplankton compartment by a multiplication with the ratio of Chl $a$ to phytoplankton biomass and assuming that only a fraction of phytoplankton growth is devoted to Chl $a$ synthesis (see details in Fennel et al. 2006).

The model is forced by a seasonal cycle atmospheric forcing. The air temperature, short-wave radiation, long-wave radiation, precipitation, cloud cover and freshwater flux used to force the model come from ERA-40 reanalysis (Uppala et al. 2005). Surface pressure come from ERA-Interim reanalysis (Dee et al. 2011). All these variables have a spatial resolution of one degree and a time resolution of 6 hours. QuickScat blind data is used for wind forcing (both zonal and meridional). The wind has a spatial resolution of a quarter of degree and a time resolution of 6 hours. The boundary conditions were obtained from NEMO (available from http://www.nemo-ocean.eu, these simulations are reported in Adani et al. 2011) and interpolated to the ROMS grid to define a sponge layer of ten horizontal grid points with a nudging relaxation time of 30 days. At the western boundary (Gibraltar Strait) NEMO climatology is set by imposing the vertical profile of salinity, temperature and zonal velocity following the methodology of Peliz et al. (2007). Biological boundary conditions are set as a vertical profile in all variables, following the methodology of Fennel et al. (2006).

The simulation domain ranges from $5.9^{\circ} \mathrm{W}$ to $1.48^{\circ} \mathrm{E}$ zonally and from $33.82^{\circ} \mathrm{N}$ to $38.88^{\circ} \mathrm{N}$ meridionally (see Fig. 1). The grid space is $2 \mathrm{~km}$ and the vertical domain is discretized using 40 vertical levels with finer resolution near the surface. The advection scheme used in our simulations is MPDATA (recursive flux corrected 3D advection of tracers, Smolarkiewicz et al. 1998) and Large-McWilliams-Doney mixing as a sub-grid scale turbulent mixing closure scheme (Large et al. 1994), also known as the K-profile parameterization scheme. The air-sea interaction used for boundary layer in ROMS is based on the bulk parameterization of (Fairall et al. 1996). 


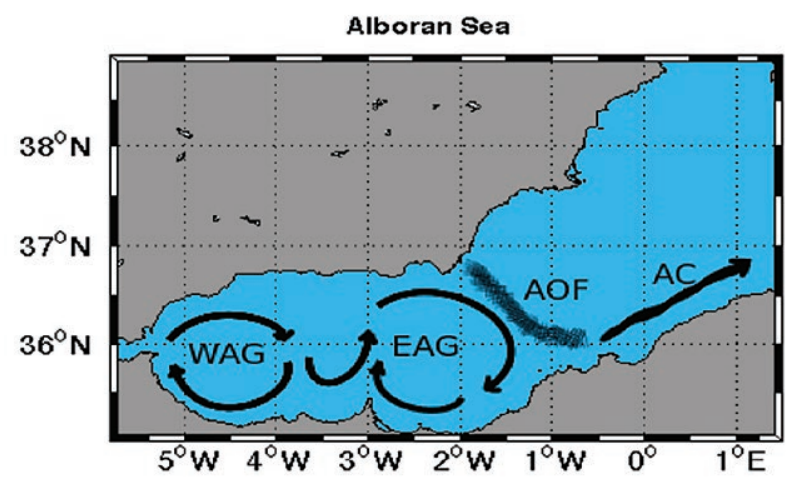

Fig. 1. - Alboran Sea simulation domain and main surface circulation patterns. WAG: Western Alboran Gyre. EAG: Eastern Alboran

Gyre. AOF: Almeria-Oran Front. AC: Algerian Current.

We ran the model using climatological atmospheric forcing and climatological boundary conditions. The initial conditions for starting the simulations were obtained using the same interpolated fields as the ones used for the boundary conditions for all variables. After an 8-year spin-up period, we used the ninth year as the study period.

The regional ROMS implementation has been already tested using satellite and cruise data in previous works (Macías et al. 2011) and was used in biological simulations in a previous paper (Catalán et al. 2013). In these works, we ran the model using both boundary conditions and atmospheric forcing climatologies to obtain a stable initial state for three years. After this spin-up period, we used the climatological initial state to begin the simulation for June, July and August 2008. However, in the present work we more than double the spin-up time period in order to assure a complete stationary state of the year analysed.

\section{Data analysis}

The model output and associated data analysis have daily time resolution. In order to relate the modelled phytoplankton (Chl $a$ ) concentration with the dynamical variables (model velocities) we proceed in four steps. First, we obtained a mean two-dimensional, vertical-averaged, time-evolving field for Chl $a, \mathrm{U}, \mathrm{V}, \mathrm{W}$ by averaging the ocean surface water column in the first 20 metres.

The 20-m layer is expected to capture the essential dynamics of surface ocean properties and also the surface Cha $a$. Previous works show that $\mathrm{Chl} a$ maxima can be deeper than 20 metres (Macías et al. 2014) in the Alboran Sea area. However, our purpose here was to obtain an estimation of what can be considered as the surface Chl $a$ variability for comparison with the satellite-based studies (Solé et al. 2012).
Second, we split these four fields into an adjusted harmonic signal (annual, semi-annual and quarterly) that we shall call 'seasonal' part (Solé et al. 2012). The data are de-trended by fitting a linear function through a non-linear least squares regression. The annual, semi-annual and quarterly cycle are removed from the original data by fitting three harmonic functions using a least squares method (Pascual et al. 2008).

$$
\begin{gathered}
y(t)=A_{a} \cos \left(\frac{2 \pi}{365.25} t-\varphi_{a}\right)+A_{s a} \cos \left(\frac{2 \pi}{182.63} t-\varphi_{s a}\right)+ \\
+A_{q} \cos \left(\frac{2 \pi}{91.31} t-\varphi_{q}\right)
\end{gathered}
$$

where $A_{\mathrm{a}}, A_{\mathrm{as}}, A_{\mathrm{q}}$, and $\varphi_{\mathrm{a}}, \varphi_{\mathrm{as}}, \varphi_{\mathrm{q}}$, are the amplitude and phase of the annual, semi-annual and quarterly cycles. Phases are expressed in days and a zero time lag indicates January 1. After removing the trend, annual and semi-annual cycle for each grid point, the empirical orthogonal functions (EOFs) of each variable are computed. EOFs are calculated using a singular value decomposition of the covariance matrix of data, and retaining as EOFs the eigenvectors associated with non-zero eigenvalues, as is explained in Navarra and Simoncini (2010). We calculate the EOF of both the seasonal and the residual components of each variable. The EOF factorization distinguishes between the spatial pattern of EOF functions and the time coefficients of EOF coefficients (von Storch and Zwiers 2001). Finally, we correlate the EOF coefficients (EOFt) of velocity $(\mathrm{U}, \mathrm{V}, \mathrm{W})$ and $\mathrm{Chl} a$ for seasonal and residual parts. The residual part is produced by the inner variability amplification of the non-linearities of the model. We therefore call it residual instead of anomaly, because this non-periodic part (residual) cannot be associated with the intra-annual variability of forcing or boundary conditions.

$$
\theta(x, y, t)=\sum_{j-1}^{n} m_{j}(x, y) A_{j}(t)
$$

where $\theta(x, y, t)$ is the seasonal or residual (original data minus trend and annual and semi-annual cycle) of the variable, and for each index $\mathrm{j}, \mathrm{m}_{\mathrm{j}}$ corresponds to the $\mathrm{j}_{\mathrm{th}}$ EOF function and $A_{\mathrm{j}}$ is its EOF coefficient (EOFt)

\section{RESULTS}

The results on the relationships between the seasonal and residual parts of the surface velocity versus the Chl $a$ field are summarised in Table 1. It is worth noting that for Chl $a$ the explained variance of the 95 percentile of the seasonal part is twice the 95 percentile of the residual. This result confirms the leading role of

Table 1. - Seasonal and residual EOFts of explained variance (Exp. Var.) of Chl $a$, zonal wind and velocity components and correlation

\begin{tabular}{|c|c|c|c|c|c|c|c|c|c|}
\hline \multirow[b]{2}{*}{$\mathrm{EOFt}$} & & \multirow{2}{*}{$\frac{\text { Chl } a}{1}$} & \multicolumn{2}{|c|}{$\mathrm{U}$} & \multicolumn{2}{|c|}{$\mathrm{V}$} & \multicolumn{2}{|c|}{ W } & \multirow{2}{*}{$\frac{\text { UWi }}{1}$} \\
\hline & & & 1 & 2 & 1 & 2 & 1 & 2 & \\
\hline & Exp. Var. (\%) & 82 & 38 & 30 & 43 & 31 & 41 & 29 & 95 \\
\hline Seasonal & Corr. with Chl $a$ & & -0.2 & 0.79 & -0.08 & 0.76 & 0.95 & -0.2 & 0.92 \\
\hline & Exp. Var. (\%) & 30 & 10 & 9 & 11 & 10 & 3 & 3 & 71 \\
\hline Residual & Corr. with Chl $a$ & & 0.69 & 0.29 & -0.3 & 0.67 & 0.25 & 0.39 & 0.22 \\
\hline
\end{tabular}
between Chl $a$ and velocity components and zonal wind seasonally shifted for 90 days and the non-shifted wind residual. The correlations over 0.5 are highlighted in bold. 

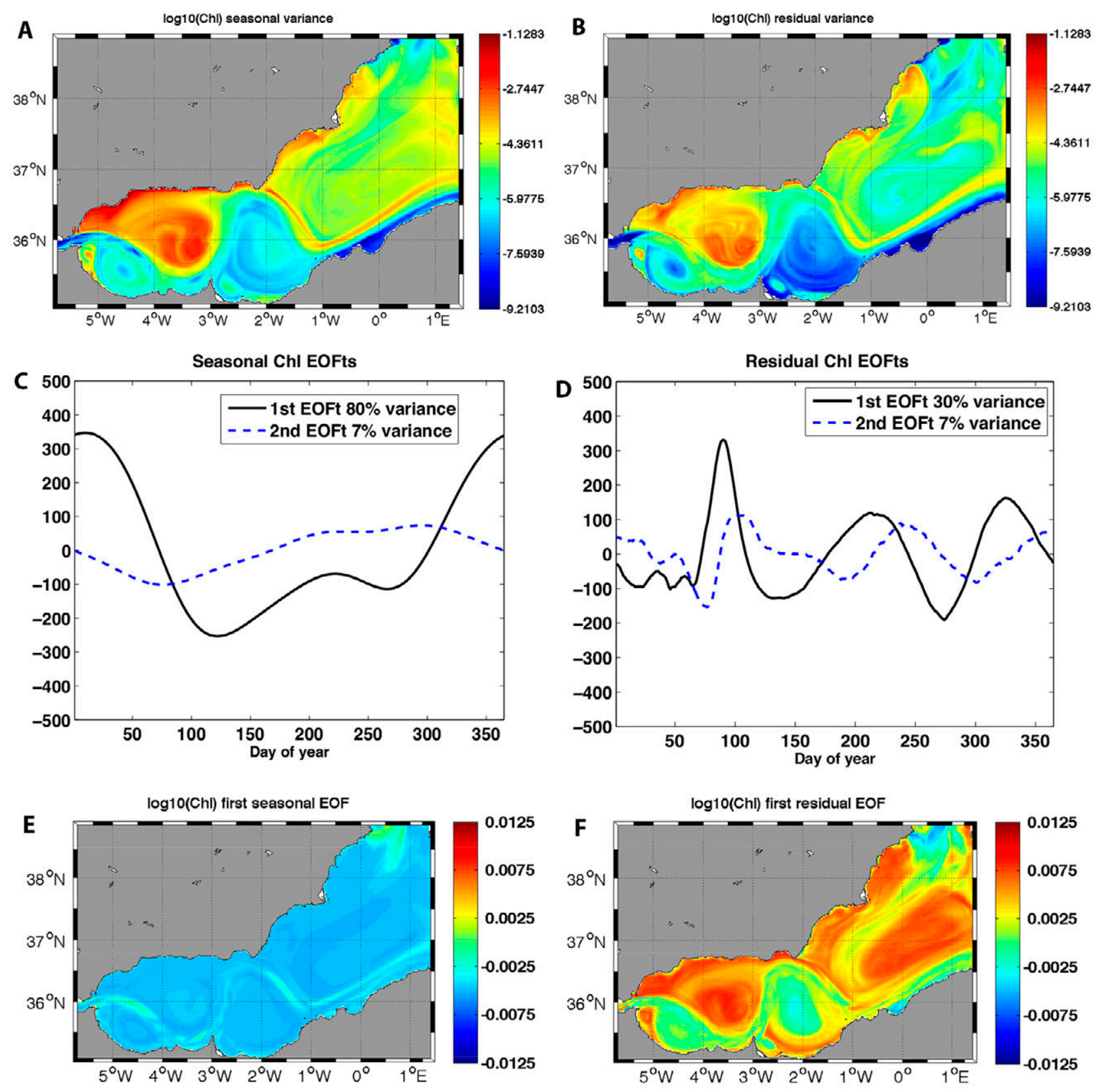

Fig. 2. - A, Chl $a$ seasonal part variance, colour in logarithmic scale; B, Chl $a$ residual part variance, colour in logarithmic scale; C, chlorophyll seasonal part first and second EOFts; D, Chl $a$ residual first and second EOFts; E, Chl $a$ first seasonal EOF; F, Chl $a$ residual first EOF.

the seasonal variability in this climate-forced simulation. However, it also gives an insight into the nonnegligible role played by the residual part representing the inner system variability due to the non-linearities of the equations.

Correlations were calculated between $\mathrm{Chl} a$ and velocity components EOFts and zonal wind. For the seasonal zonal wind correlation calculation, a temporal shift of 90 days was applied. The zonal wind residual was non-shifted. Correlations over 0.9 were found between the first EOFt of the seasonal Chl $a$ and the first EOFt of both seasonal zonal wind and seasonal ocean vertical velocity. This indicates the intimate link between the main mode of variability of Chl $a$, zonal wind and ocean vertical velocity seasonal patterns, which is shown by a high correlation between the seasonal shifted (90 days) vertical velocity and seasonal wind ( 0.89 correlation coefficient).

As expected, the eigenvalue spectra of the residual fields (not shown) showed an almost uniform distribution of the explained variance among all the modes (around the 10\%). The correlation between the EOFt series of Chl $a$ and the dynamical variables studied was larger than 0.6 only for the horizontal ocean velocities ( $\mathrm{U}$ and $\mathrm{V}$ ). The residual zonal wind did not have a significant correlation with the residual Chl $a(0.22)$.

The coastal upwelling signal was better captured by the seasonal part, while the variance of the residual part was larger off-shore (Figs 2A, B). Figure 2C-F shows the two leading EOFts and EOFs of the seasonal and 

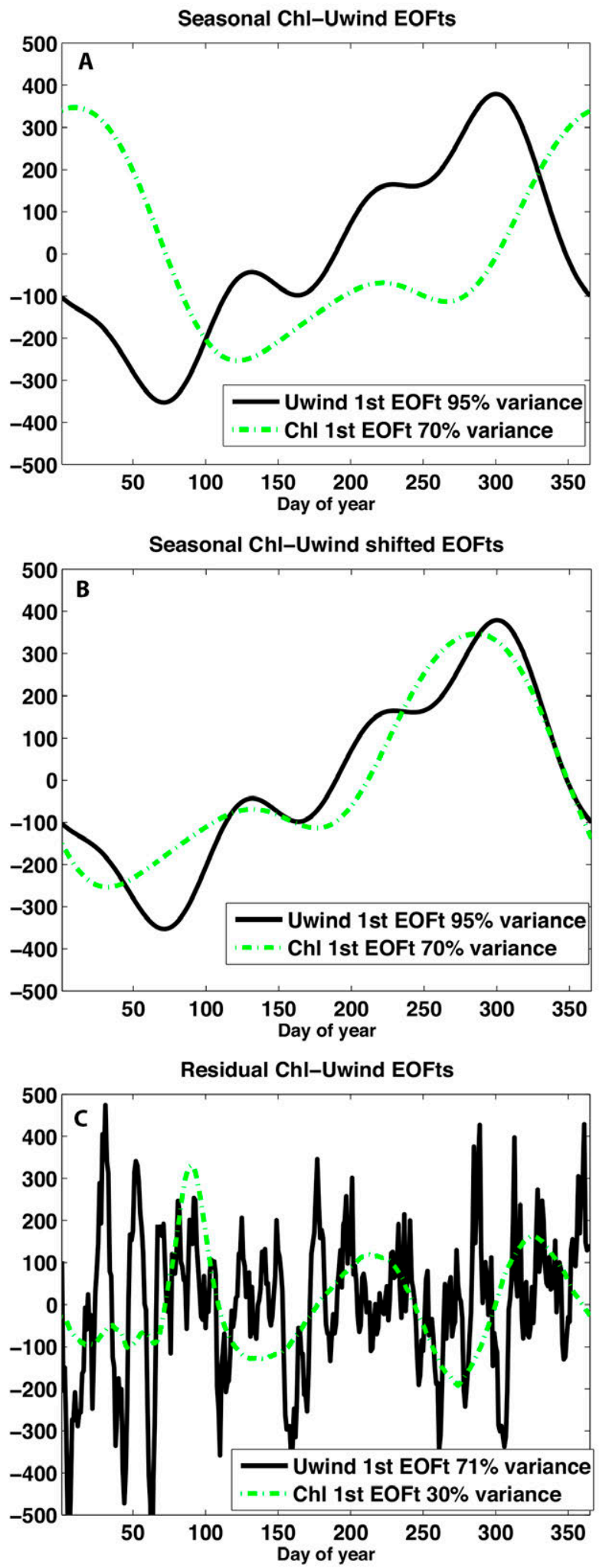

Fig. 3. - A, Chl $a$ and zonal wind seasonal part first EOFts; B, Chl $a$ and zonal wind seasonal part first EOFts with a temporal shift (time lag) of 90 days is applied only in this case; C, Chl $a$ and wind first residual EOFts.

residual Chl $a$. The largest amplitude of the leading EOF of the seasonal Chl $a$ was located in the southern Iberian Peninsula coastal upwelling areas while the EOF amplitude of the first EOF of the residual Chl $a$ was located off-shore, near the axis of the jet, gyres and frontal structures.

The first EOFt of the Chl $a$ seasonal part (representing $80 \%$ of the seasonal variance) had its maximum in winter and its minimum in spring-summer, in coherence with the typical seasonal variability observed in the area (Macías et al. 2008), while the second EOFt showed an opposite phase with lower amplitude (Macías et al. 2007). The first two EOF coefficients of residuals (with higher frequency oscillation than the seasonal EOFts) are shown in Figure 2D and represent $30 \%$ and $7 \%$ of the total explained variance. Figure $2 \mathrm{~F}$ shows the first EOF of the Chl $a$ residual logarithm. The first EOF of seasonal part (Fig. 2E) showed high variability values in the areas related to the Atlantic Jet and Algerian Current fronts, while the first EOF of the residuals (Fig. 2F) showed a contribution to all dynamic structures in its variability but with clearly different values in the gyres and the Algerian Current from those of the coastal and open ocean structures.

The temporal evolution of the first EOFts of both seasonal parts seems to evolve with a time lag in Chl $a$ (Fig. 3A). When a lag of 90 days is applied to Chl $a$ (Fig. 3B), the seasonal chlorophyll and zonal wind variability are in phase, although wind oscillations shorter than four months are not corresponded by Chl $a$ first mode. The time lag of 90 days indicates the indirect link of wind-Chl $a$ variability through vertical velocity variability. This could indicate the cumulative effect of the wind to influence Chl $a$ long-term variability (more than two weeks): the response of the whole ocean system to the wind forcing needs to 'accumulate' enough energy to effectively respond to changes in the atmosphere. The first EOF coefficients of the residuals, represented in Figure 3C, show different oscillating frequencies in both variables, in coherence with the correlations shown in the Table 1.

In Figure 4 no time lag was applied. the first EOFt of Chl $a$ and the second EOFt of U and V are shown.

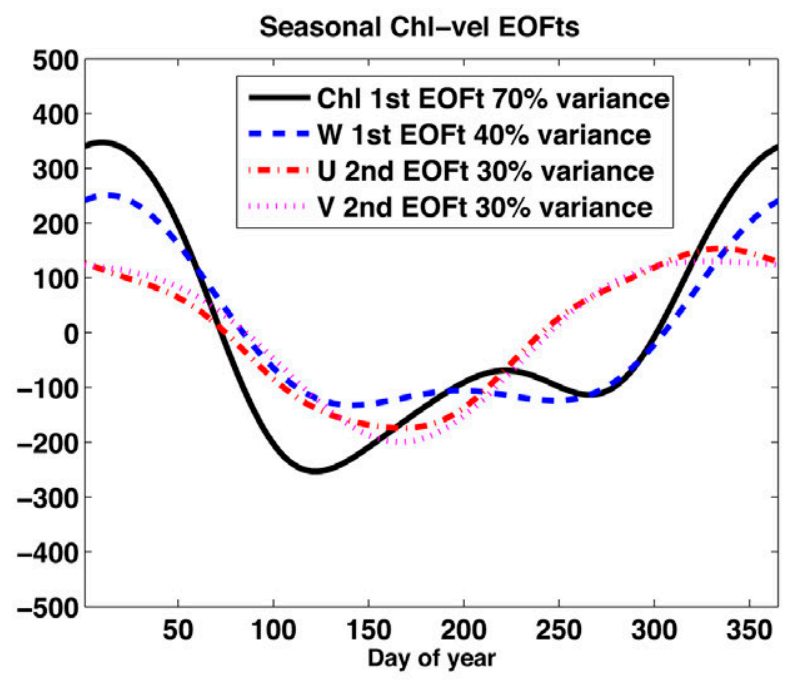

Fig. 4. - Seasonal EOFts of ocean components (without time lag): first EOFt of Chl $a$ and W, second EOFt of $\mathrm{U}$ and V. 

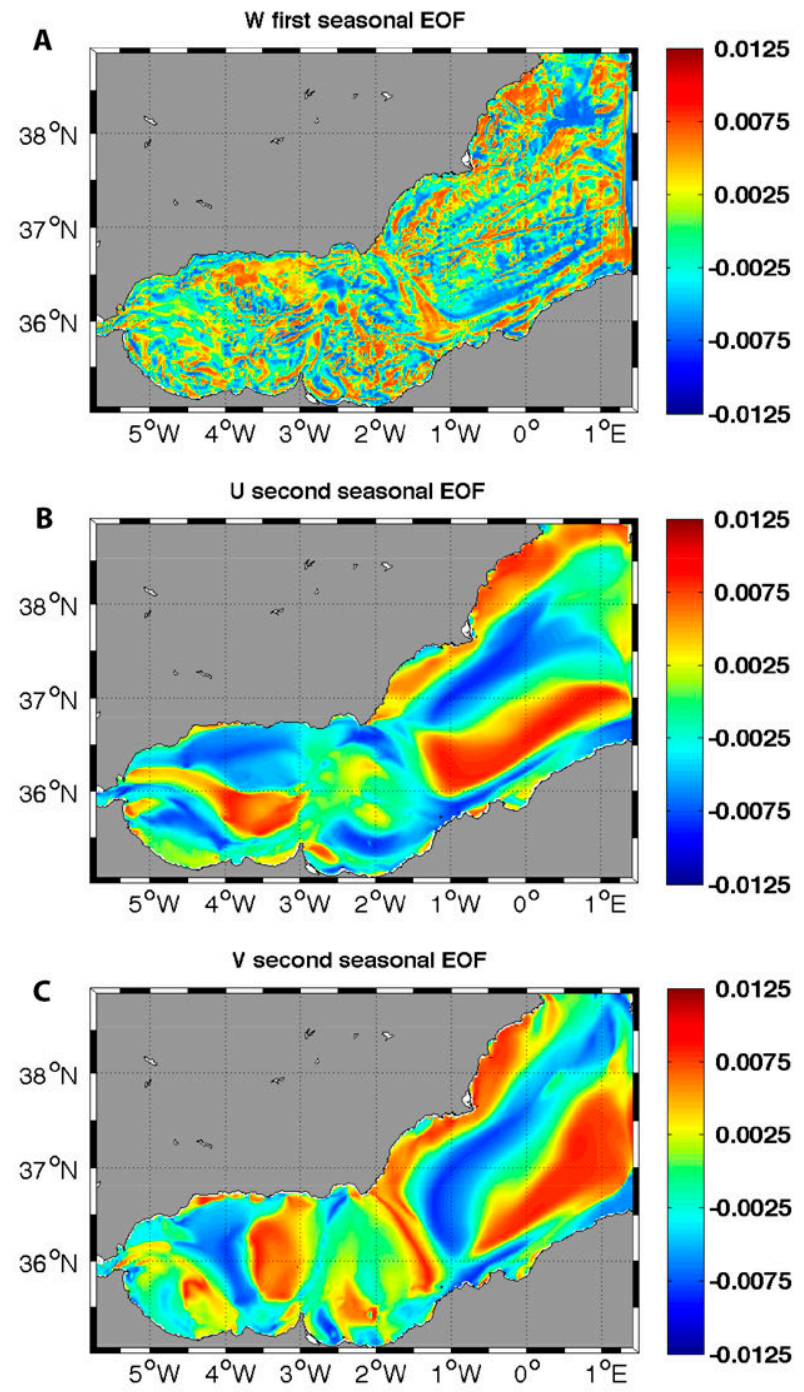

Fig. 5. - A, first EOFs of seasonal W; B, second EOFs of U; and C, second EOFs of $\mathrm{V}$.

The time series of the vertical velocity mode reproduces the periods of oscillation of the leading Chl $a$ mode. The horizontal velocity component modes only show the typical yearly oscillation coincidence in maxima and minima. Figure 5 shows the EOF functions associated with the previous coefficients. The first EOF of $\mathrm{W}$ is shown in Figure 5A, which represents a noisier pattern than that associated with the Chl $a$ or the horizontal velocity components. Although noisy, signals associated with the AOF and the Algerian Current can be distinguished. Also, the area associated with the Malaga upwelling (between the WAG and Eastern Alboran Gyre (EAG), southern coastal area of Iberian Peninsula) can be clearly identified. The second EOF functions of U (Fig. 5B) and $\mathrm{V}$ (Fig. 5C) show mainly the structures associated with WAG and AOF in correspondence with the first EOF structures of the Chl $a$ field (Fig. 2A).

The most correlated EOFt components of the $\mathrm{Chl} a$ and horizontal velocities residuals are: the first mode of zonal velocity, and the second mode of the meridional velocity (Fig. 6). In this case, the coincidence

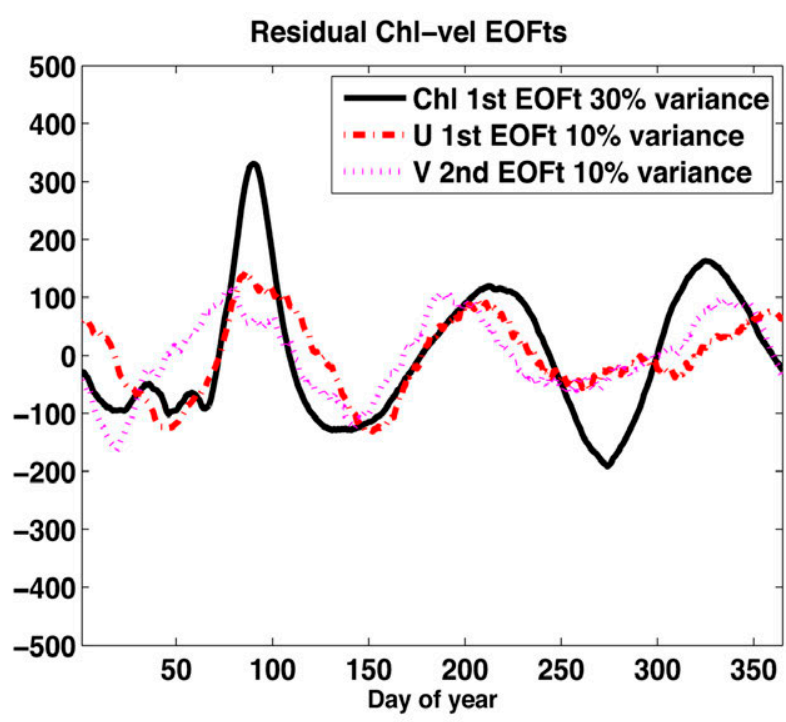

Fig. 6. - Residual first EOFts of $\mathrm{Chl} a$, first EOFt of $\mathrm{U}$ and second EOFt of $\mathrm{V}$.

between the time series is significant. In Figure 7 the first $\mathrm{EOF}$ of residual $\mathrm{U}$ (Fig. 7A) and the second $\mathrm{EOF}$ of residual $\mathrm{V}$ (Fig. 7B) are shown. The first EOF of residual Chl $a$ has already been shown in Figure 2B; note that while the zonal velocity EOF contains EAG and AOF patterns (Fig. 7A), the meridional EOF (Fig. 7B) shows an area of southward velocities (dark blue shade in the off-shore region of Malaga coast and dark blue-green in the Almeria coast and off-shore region). In both off-shore zones (Malaga and Almeria) this meridional velocity component will contribute to the transport off-shore of the seasonal $\mathrm{Chl} a$ produced in the coastal upwelling.

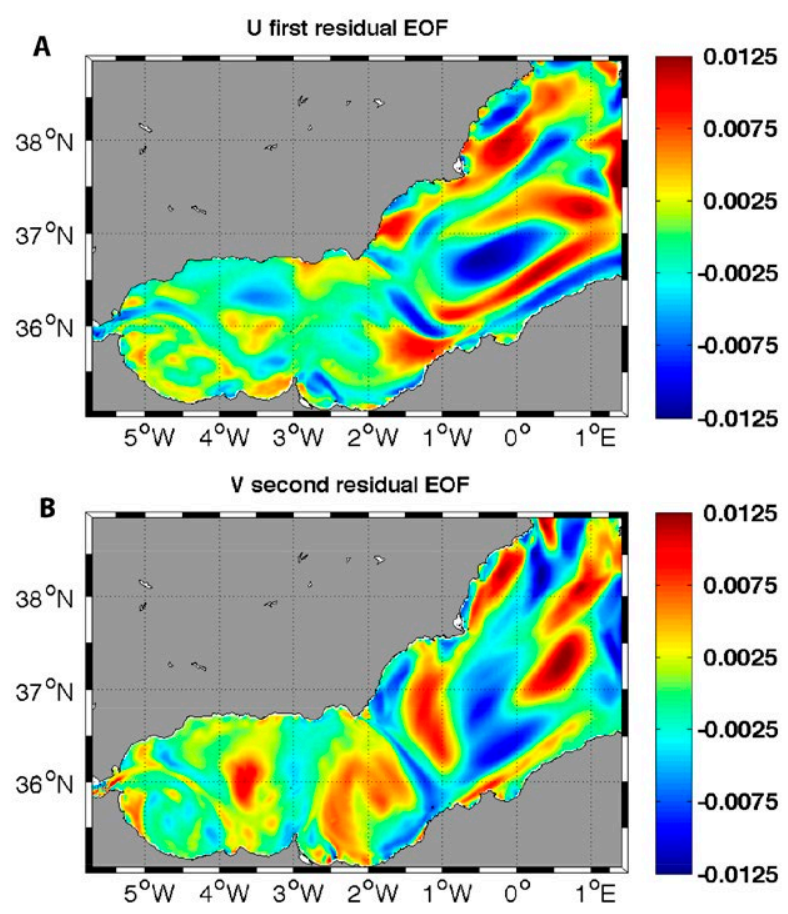

Fig. 7. - A, first residual EOF of U; B, and second residual EOF of $\mathrm{V}$. 


\section{DISCUSSION}

In this work we have studied the physical mechanisms that can drive Chl $a$ blooms in the Alboran Sea. Previous studies had emphasized the role of wind (mainly the zonal component) in the Alboran Sea primary production. Macías et al (2007) related the Chl $a$ variability to seasonal winds and their effect on the upwelling area off the Malaga coast. The main ocean mechanism was linked to the role played by the Atlantic Jet entrance and its meridional displacement, reinforcing or weakening the coastal upwelling. A more recent work (Oguz et al. 2015) developed that view with a modelling study showing that the impact of the Atlantic Jet meandering enhances plankton production by means a non-linear mechanism, which is developed through a strong ageostrophic cross-frontal circulation. This dynamic process supplies nutrients into the euphotic layer and then stimulates phytoplankton growth along the jet. Thus, following these previous studies, the main mechanism enhancing the Chl $a$ in the basin is supplied by the vertical velocities in the upwelling coastal region or by the non-linearities in the Atlantic Jet ageostrophic cross-frontal circulation. The seasonal and residual contribution of vertical versus horizontal velocity components to the total Chl $a$ variability of the system has been analysed. Although previous works have analysed the role of the zonal winds in enhancing Chl $a$ blooms at the seasonal scale (Macías 2007, 2008), recent works have suggested that the residual contribution to the total $\mathrm{Chl} a$ variability may also have a significant contribution (Solé et al. 2012).

To further analyse these mechanisms, we split the contribution of upwelling-enhanced $\mathrm{Chl} a$ production and the non-linear contributions by separating the modelled output data in a seasonal contribution and a residual (non-seasonal) contribution. This approach is similar to the one used by Macías et al. (2007) and Solé et al. (2012), which found a strong influence of the wind in the enhancement of Chl $a$ seasonal behaviour. Moreover, Macías et al. (2011) related the vertical component of the velocity field with the upwelling of the coastal area, which in turn, is produced by the southern displacement of the Atlantic Jet. However, he role of the horizontal velocities in the $\mathrm{Chl} a$ production and dispersion and his periodicity remained unclear. Our methodology clarifies the role of the seasonal and the residual part of the surface velocity field linked to the Chl $a$ variability.

Using an EOF analysis we found that while seasonal Chl $a$ behaviour is strongly related to the vertical velocities in the upwelling area, residual two-dimensional horizontal components are related to non-seasonal Chl $a$ behaviour. These results support previous results (Sarhan et al. 2000, Macías et al. 2007, 2011, Solé et al. 2012, Oguz et al. 2015) and further provide a quantification on when and how each of the velocity components acts and in what sub-area of the Alboran Sea these velocity components play a major role.

The residual part of the three-dimensional velocity field therefore acts as a response to the instabilities or perturbations in the mean structures of the Alboran
Sea: the Atlantic Jet, WAG, EAG and AOF. The seasonal component of the variability accounts for these stable structures and the residual component accounts for their short-term variability. In terms of the velocity field, the off-shore transport of the $\mathrm{Chl} a$ produced in coastal areas is driven by the horizontal components of the velocity field. However, horizontal velocity components also account for the transport of biomass through the Gibraltar Strait. The physical mechanisms acting on this three-dimensional velocity field are advection and continuity of vertical-horizontal velocity components. The dominant component of advection is related to the horizontal velocity components while the vertical velocity components are related to the continuity equation.

Our results also quantify the relative contribution of these two time scales, showing that the modelled residual contribution of $\mathrm{Chl} a$ to total variability is only half the seasonal one. In addition, we show that the connection between wind and seasonal Chl $a$ production in coastal areas of the southern Iberian Peninsula is due to ocean vertical velocity. This finding is quantified by the high correlation between EOFts of the seasonal part of Chl $a$ and vertical velocity. This correlation can be explained by the upwelling in southern Iberian coastal area (the Malaga and Almeria coast), which brings nutrients to the euphotic zone.

The spatial extension of $\mathrm{Chl} a$ coastal blooms has been shown to be controlled by the residual horizontal components of the ocean velocity field, and particularly by the meridional horizontal component acting off the Malaga and Almeria coasts. Correlation with the residual part of $\mathrm{Chl} a$ and the meridional velocity EOFt component shows these driving mechanisms of ocean velocity on Chl $a$. A possible interpretation of this phenomena can be given in terms of the role and time scales of the upwelling blooms. Once a bloom occurs in the coastal upwelling area, horizontal velocities (and particularly meridional ones) will transport the Chl $a$-rich water off-shore until it meets ocean surface structures such as the EAG, WAG and AOF, which act as dynamic barriers to surface-advected Chl $a$. This is also in good agreement with the patterns observed in satellite images of ocean colour (Solé et al. 2012).

The main results of this work have shown the importance of the contribution of the horizontal velocity residuals in accounting for the $\mathrm{Chl} a$ patterns in the area. It has been shown that $\mathrm{Chl} a$ variability is dominated by a seasonal part driven by coastal upwelling in winter. However, ocean velocity residuals play a key role in horizontal $\mathrm{Chl} a$ advection off-shore. This contribution should be considered within the percentage of explained variance of the residual, which is estimated to be half the contribution of seasonal part.

\section{ACKNOWLEDGEMENTS}

JS was funded by the Spanish Ministry of Science and Innovation (through the MedEX project CTM2008-04036-E/MAR) and the EU project MarineVectors project FP7-KBBE 266445. JS acknowledges a CSIC JAE-Doc contract co-funded by the FSE. We 
also wish to acknowledge the useful comments of Manuel Vargas and one anonymous referee, which helped to improve the manuscript.

\section{REFERENCES}

Adani M., Dobricic S., Pinardi N. 2011. Quality assessment of a 1985-2007 Mediterranean Sea reanalysis. J. Atm. Ocean. Techn. 28: 569-589. http://dx.doi.org/10.1175/2010JTECHO798.1

Baldacci A., Corsini G., Grasso R., et al. 2001. A study of the Alboran sea mesoscale system by means of empirical orthogonal function decomposition of satellite data. J. Mar. Syst. 29: 293-311. http://dx.doi.org/10.1016/S0924-7963(01)00021-5

Catalán I., Macías D., Solé J., et al. 2013. Stay off the motorway: Resolving the pre-recruitment life history dynamics of the European anchovy in the SW Mediterranean through a spatially-explicit individual based model (SEIBM). Progr. Oceanogr. 111: $140-153$ http://dx.doi.org/10.1016/j.pocean.2013.02.001

Coble P.G. 2007. Marine optical biogeochemistry: The chemistry of ocean color. Chem. Rev. 107: 402-418. http://dx.doi.org/10.1021/cr050350+

Dee D.P., Uppala S.M., Simmons A.J., et al. 2011. The ERA-Interim reanalysis: configuration and performance of the data assimilation system. Q. J. R. Meteorol. Soc. 137: 553-597. http://dx.doi.org/10.1002/qj.828

Estrada M. 1985. Fitoplàncton i producció primària a la Mediterrània occidental. Diputació de Barcelona. Quad. Ecol. Apl. 8: 99-109.

Fairall C., Bradley E., Rogers D., et al. 1996. Bulk parameterization of air-sea fluxes for tropical ocean-global atmosphere coupled-ocean atmosphere response experiment. J. Geophys. Res. 101: 3747-3764. http://dx.doi.org/10.1029/95JC03205

Fennel K. Wilkin J., Levin J., et al. 2006. Nitrogen cycling in the Middle Atlantic Bight: Results from a three-dimensional model and implications for the North Atlantic nitrogen budget. Global Biogeochem. Cycles 20: GB3007. http://dx.doi.org/10.1029/2005GB002456

GEOHAB group. 2005. Global ecology and oceanography of Harmful algal Blooms. Technical report, SCOR, IOC Unesco. GEOHAB Core Res. Proj.: Habs In Upwelling Systems.

Large W., McWilliams J., Doney S. 1994. Oceanic vertical mixing: a review and a model with a nonlocal boundary layer parameterization. Rev. Geophys. 32: 363-403.

Macías D., Navarro G., Echevarría F., et al. 2007. Phytoplankton pigment distribution in the northwestern Alboran Sea and meteorological forcing: A remote sensing study. J. Mar. Res. 65: 523-543. http://dx.doi.org/10.1357/002224007782689085

Macías D., Bruno M., Echevarría F., et al. 2008. Meteorologically-induced mesoscale variability of the north-western Alboran Sea (Southern Spain) and related biological patterns. Est. Coast. Shelf Sci. 78: 250-266. http://dx.doi.org/10.1016/j.ecss.2007.12.008

Macías D., Catalán I., Solé J., et al. 2011. Atmospheric-induced variability of hydrological and biogeochemical signatures in the NW Alboran Sea. Consequences for the spawning and nursery habitats of European anchovy. Deep-Sea Res. 58: 1175-1188. http://dx.doi.org/10.1016/j.dsr.2011.08.013

Macías D., Castilla-Espino D., García-del-Hoyo J.J., et al. 2014. Consequences of a future climatic scenario for the anchovy fishery in the Alboran Sea (SW Mediterranean): A modeling study. J. Mar. Syst. 135: 150-159. http://dx.doi.org/10.1016/j.jmarsys.2013.04.014

Mahadevan A., Thomas L., Tandon A. 2008. Comment on "Eddy/ Wind Interactions Stimulate Extraordinary Mid-Ocean Plankton Blooms. Science 320: 448 . http://dx.doi.org/10.1126/science.1152111
Marra J. 1980. Vertical Mixing and Primary Production. In: Primary Productivity in the Sea. Environmental Science Research series 19. Springer US. pp. 121-137. http://dx.doi.org/10.1007/978-1-4684-3890-1_7

McGillicuddy D.J., Anderson L.A., Bates N.R., et al. 2007. Eddy/ Wind Interactions Stimulate Extraordinary Mid-Ocean Plankton Blooms. Science 316: 1021-1026. http://dx.doi.org/10.1126/science.1136256

McGillicuddy D.J., Ledwell J.R. Anderson L.A. 2008. Response to Comment on 'Eddy/Wind Interactions Stimulate Extraordinary Mid-Ocean Plankton Blooms'. Science 320: 448. http://dx.doi.org/10.1126/science.1148974

Navarra A., Simoncini V. 2010. A Guide to Empirical Orthogonal Functions for Climate Data Analysis. Springer. http://dx.doi.org/10.1007/978-90-481-3702-2

Nieves V., Llebot C., Turiel A., et al. 2007. Common turbulent signature in sea surface temperature and chlorophyll maps. Geophys. Res. Lett. 62: 2-5. http://dx.doi.org/10.1029/2007g1030823

O’Reilly J.E., Maritorena S., Mitchell B.G., et al. 1998. Ocean color chlorophyll algorithms for seaWIFS. J. Geophys. Res. Oceans 103(C11): 24937-24953. http://dx.doi.org/10.1029/98JC02160

Oguz T., Macias D., Tintoré J. 2015. Ageostrophic Frontal Processes Controlling Phytoplankton Production in the Catalano-Balearic Sea (Western Mediterranean). PLoS ONE 10: e0129045. http://dx.doi.org/10.1371/journal.pone.0129045

Pascual A., Marcos M., Gomis D. 2008. Comparing the sea level response to pressure and wind forcing of two barotropic models: validation with tide gauge and altimetry data. J. Geophys. Res. Oceans 113. http://dx.doi.org/10.1029/2007jc004459

Patti B., Guisande C., Vergara A., et al. 2008. Factors responsible for the differences in satellite-based chlorophyll a concentration between the major global upwelling areas. Est. Coast. Shelf Sci. 76: 775-786. http://dx.doi.org/10.1016/j.ecss.2007.08.005

Peliz A., Dubert J., Marchesiello P., et al. 2007. Surface circulation in the Gulf of Cadiz: Model and mean flow structure. J. Geophys. Res. 112: 429-436. http://dx.doi.org/10.1029/2007JC004159

Powell T.P., Lewis C.V., Curchister E.N., et al. 2006. Results from a three-dimensional, nested biological-physical model of the California Current System and comparisons with statistics from satellite imagery. J. Geophys. Res. 111: 1877-1898. http://dx.doi.org/10.1029/2004JC002506

Sarhan T.J., García Lafuente M., Vargas J.M., et al. 2000. Upwelling mechanisms in the northwestern Alboran Sea. J. Mar. Syst. 23: 317-331.

Shchepetkin A., McWilliams J. 2003. A Method for Computing Horizontal Pressure-Gradient Force in an Oceanic Model with a Non-Aligned Vertical Coordinate. J. Geophys. Res. 108: 3090. http://dx.doi.org/10.1029/2001JC001047

Shchepetkin A., McWilliams J. 2005. The Regional Ocean Modeling System (ROMS): A split-explicit, free-surface, topography-following coordinates ocean model. Ocean Model. 9: 347-404.

http://dx.doi.org/10.1016/j.ocemod.2004.08.002

Smolarkiewicz P.K., Margolin L.G. 1998. MPDATA: A finite-difference solver for geophysical flows. J. Comput. Phys. 140: 459-480. http://dx.doi.org/10.1006/jcph.1998.5901

Solé J., Ruiz S., Pascual A., et al. 2012. Ocean color response to wind forcing in the Alboran Sea: A new forecasting method. J. Mar. Syst. 98: 1-8. http://dx.doi.org/10.1016/j.jmarsys.2012.02.007

Uppala S.M., Kållberg P.W., Simmons A.J., et al. 2005. The ERA40 re-analysis. Q. J. R. Meteorol. Soc. 131: 2961-3012. http://dx.doi.org/10.1256/qj.04.176

von Storch H., Zwiers F.W. 2001. Statistical Analysis in Climate Research, Cambridge Univ. Press, 484 pp. 